\title{
Small-intestinal bleeding due to metastatic renal cell cancer
}

A 68-year-old man who presented with obscure occult gastrointestinal bleeding was referred to our department to undergo capsule endoscopy. He had a history of clear-cell renal carcinoma (pT2NxM0EII), for which he had undergone a radical nephrectomy 1 year before. No adjuvant radiation or chemotherapy was administered. At 5 days before capsule endoscopy was due to be performed, he developed melena and required blood transfusion. Laboratory data revealed an iron deficiency anemia, with a hemoglobin level of $7.8 \mathrm{~g} / \mathrm{dL}$.

Capsule endoscopy of the small bowel revealed an active hemorrhage due to an ulcerated mass at the proximal jejunum (๑ Fig. 1).

Enteroscopy confirmed the bleeding tumor, which was excised immediately (৫ Video 1 ).

The pathology was consistent with clearcell renal metastases to the small bowel.

Secondary tumors of the gastrointestinal tract are unusual but are probably more common than clinically suspected. The most common primaries include melanoma, lung, breast, and ovarian carcinomas, and choriocarcinomas.

Intraluminal small-bowel metastases from metastatic renal cancer are not commonly seen, but based on autopsy data the incidence may be $0.7 \%-14.6 \%$ [ $1-4]$. The interval from initial nephrectomy to presentation of intestinal metastases is reported to range from 3 months to 20 years, and appears to correlate with overall disease-specific survival. Intestinal metastases occur equally in the jejunum and the ileum, and usually present with intestinal

\section{Video 1}

Enteroscopy showing the small-bowel tumor.

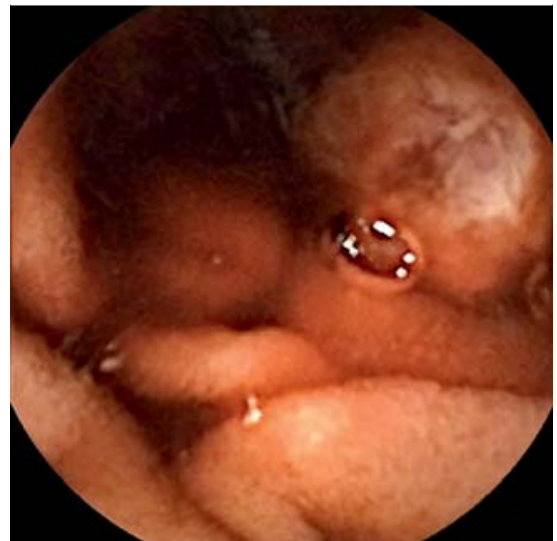

Fig. 1 Endoscopy capsule view of an active hemorrhage due to an ulcerated mass.

bleeding due to tumoral invasion of intestinal vessels [5].

This current case is of interest because its demonstrates the clinical and endoscopic characteristics of an unusual small-bowel tumor. Capsule endoscopy allowed not only the detection of the site of active bleeding but also the diagnosis of the intestinal mass. The early use of this device shortened the patient's diagnostic work-up and subsequent management.

Endoscopy_UCTN_Code_CCL_1AC_2AC

Competing interests: None

C. Vazquez ${ }^{1}$, J. Berrueta ${ }^{1}$, F. De Simone ${ }^{1}$,

A. Tcheckmedyian ${ }^{1}$, N. Gonzalez ${ }^{1}$,

J. Bernachin ${ }^{2}$, A. Perrota ${ }^{3}$, J. Curi ${ }^{3}$,

A. Mariño ${ }^{2}$, C. Olano ${ }^{1}$

1 Gastroenterology Clinic

“Prof. H. Cohen”, Hospital de Clínicas, Montevideo, Uruguay

2 Laboratory of Histopathology, Hospital de Clínicas, Montevideo, Uruguay

3 Department of Surgery, Hospital de Clínicas, Montevideo, Uruguay
References

1 Pavlakis GM, Sakorafas GH, Anagnostopoulos $G K$. Intestinal metastases from renal cell carcinoma: a rare cause of intestinal obstruction and bleeding. Mt Sinai J Med 2004; 71: $127-130$

2 Merino C, Moles JR, Rodrigo A et al. [Uncommon etiology of gastrointestinal bleeding: duodenal metastases from renal cell carcinoma.] Gastroenterol Hepatol 2005; 28: $221-224$

3 Weiss L, Harlos JP, Torhorst J et al. Metastatic patterns of renal carcinoma: an analysis of 687 necropsies. J Cancer Res Clin Oncol 1988; 114: 605-612

4 Pezzoli A, Matarese V, Boccia S et al. Gastrointestinal bleeding from gastric metastasis of renal cell carcinoma, treated by endoscopic polypectomy. Endoscopy 2007; 39 (Suppl 1): E52

5 Sridhar SS, Haider MA, Guindi M, Moore MJ. A case of small bowel obstruction due to intraluminal metastases from metastatic renal cell cancer. Oncologist 2008; 13: 95-97

Bibliography

DOI $10.1055 / \mathrm{s}-0030-1255821$

Endoscopy 2011; 43: E13

(c) Georg Thieme Verlag KG Stuttgart · New York . ISSN 0013-726X

Corresponding author

C. Olano, MD

Gastroenterology Clinic "Prof. H. Cohen"

Hospital de Clínicas

Av Italia s/n Piso 4

Montevideo 11600

Uruguay

Fax: +598-2-4808472

carolinaolano@movinet.com.uy 